\title{
Data Mining Penjualan Tanaman Hias dengan Algoritma APRIORI Pada Toko Flores Elishabet
}

\author{
Yendrizal \\ Program Studi Teknik Komputer, AMIK Kosgoro, Kota Solok, Indonesia \\ Email: yendrizal70@gmail.com
}

\begin{abstract}
Abstrak-Penerapan data mining sangat berguna dalam penjualan tanaman hias dan dapat mempengaruhi naik turunnya omset penjualan tanaman hias, banyaknya jenis tanaman hias dan jenis bunga beserta namanya yang berbeda-beda membuat masyarakat peminat tanaman hias bingung dalam pencarian jenis tanaman hias yang akan dibeli. Semakin tingginya minat pembelian tanaman hias membuat semakin besarnya data dan informasi yang harus diketahui serta digali upaya mengetahui jenis tanaman hias mana yang paing banyak peminat, biasanya masyarakat tidak hanya membeli satu jenis tanaman hias saja melainkan ada jenis tanaman hias lain yang ikut serta dibeli. Algoritma Apriori merupakan algoritma dalam pengambilan data menggunakan aturan asosiasi yang bertujuan untuk menentukan hubungan asosiatif dari suatu kombinasi item, data mining itu sendiri merupakan cara koputerisasi dalam strategi pemasaran.
\end{abstract}

Kata Kunci: Data Mining, Algoritma Apriori, Tanaman Hias

Abstract-The application of data mining is very useful in the sale of ornamental plants and can affect the ups and downs of the sales turnover of ornamental plants, the many types of ornamental plants and types of flowers and their different names make people interested in ornamental plants confused in the search for ornamental plants to be purchased. The higher interest in purchasing ornamental plants makes the amount of data and information that needs to be known and explored efforts to find out which type of ornamental plant that has a lot of interest, usually people not only buy one type of ornamental plant, but there are also other types of ornamental plants that are also purchased. Apriori algorithm is an algorithm in data retrieval using association rules that aim to determine the associative relationship of a combination of items, data mining itself is a way of computerization in marketing strategies.

Keywords: Data Mining, Apriori Algorithm, Ornamental Plants

\section{PENDAHULUAN}

Saat ini global warming atau yang disebut dengan pemanasan global yang terjadi akibat polusi udara yang Saat ini global warming atau yang disebut dengan pemanasan global yang terjadi akibat polusi udara yang memburuk, pembuatan rumah kaca, terutama banyak terjadinya penebangan pohon secara liar yang membuat dunia kehilangan pasokan oksigen yang diperoleh dari tanaman hijau dan mengakibatkan banyak terjadi bencana alam yang sangat mengerikan seperti terjadinya longsor, banjir yang tidak terbendung disaat musim hujan karena tidak adanya pohonatau tanaman sebagai penyerap air hujan, suhu panas yang extream yang diakibatkan oleh tipisnya lapisan ozon dan banyak hal lainnya sehingga wajib dilakukan pembenahan terhadap lingkungan[1].

Hal tersebut membuat pemerintah menggalakan untuk mengajak setiap organisasi dan masyarakat setempat untuk bersama-sama melakukan kegiatan "Go Green", go green itu sendiri merupakan cara menyelamatkan bumi ini dari kerusakan-kerusakan yang dibuat oleh tangan manusia atau menciptakan lapangan hijau atau minimal setiap orang menanam satu pohon atau dapat memiliki satu tanaman dan berlaku hingga sekarang, dari itu membuat penjual tanaman hias mendapat pesanan yang sangat banyak terutama pada hari libur[2].

Toko Flores Elishabet merupakan toko tanaman hias yang menyediakan banyak jenis tanaman baik tanaman biasa yang didesain sedemikian rupa dari yang ukuran pohon sangat besar dapat dibuat menjadi pohon berukuran kecil yang dapat memiliki buah layaknya pohon yang berukuran besar dan banyak juga Toko Flores Elishabet menjual tanaman lain yaitu jenis tanaman yang dapat diletakkan di dalam ruangan maupun di luar ruangan, Masalah yang dihadapi oleh Toko Flores Elishabet yaitu sering terjadinya kesalahan pengriman jenis tanaman hias yang mengakibatkan kerugian terhadap transportasi pengantaran tanaman hias karena tata letak bunga yang belum tersusun, sering terjadi kekosongan stok karena terlalu banyak jenis bunga yang ada pada Toko Flores Elishabet dan tidak adanya data yang memastikan kekosongan salah satu jenis tanaman hias, menggunakan data mining dalam.

Minat pembeli sangat tinggi terhadap tanaman hias yang disediakan oleh Toko Flores Elishabet dilakukan juga menggunakan sistem online (e-commerce) [3], yang membuat semakin banyak data dan informasi yang wajib diketahui oleh pihak Toko Flores Elishabet data-data dan informasi tersebut berupa penyediaan pasokan tanaman hias yang akan dijual kembali, jenis tanaman hias mana sajakah yang sering dibeli secara bersamaan juga harus diketahui agar pembeli dan penjual lebih mudah mentata letak ruangan antra tanaman hias satu dengan tanaman hias lain yang akan menjadi pajangan secara berdampingan.

Upaya tersebut juga dapat mempengaruhi terhadap tingkat penjualan pada Toko Flores Elishabet dan dianggap lebih mudah menemukan tanaman hias yang banyak diminati oleh para pembeli tanaman hias dan itu juga merupakan salah satu strategi dalam pesaingan bisnis agar mudah menemukan tanaman hias yang paling banyak diminati dan salah satu cara mengatasi adanya ketersediaan tanaman hias pada toko Flores Elishabet, strategi tersebut dapat dilakukan menggunakan Data Mining. 
Data Mining merupakan cara komputerisasi dalam proses pencarian data yang sangat banyak atau berupa big data untuk memperoleh suatu informasi yang diperlukan data mining juga digunakan dalam menentukan sebuah keputusan[4][5]. Cara yang dilakukan dalam data mining itu sendiri yaitu mencari pola atau suatu informasi yang menarik dalam suatu data yang sudah tersedia dengan menggunakan teknik beberapa metode atau sebuah algoritma dan dalam data mining juga terdapat beberapa penggunaan Algoritma berupa algoritma C4.5, algoritma Aritma, algoritma Naïve Bayes, algoritma Rough Set dan banyak lainnya. Penggunaan data mining dalam studi kasus ini menggunakan algoritma Apriori dalam membantu strategi penjalan tanaman hias[6].

Algorima Apriori merupakan algoritma yang menggunakan aturan asosiatif (Association Rule) dalam menentukan suatu hubungan asosiatif dalam suatu kombinasi item set. Algoritma Apriori biasa digunakan dalam teknik pencarian aturan-aturan hubungan berupa data-data penjulan atau transaksi, atau suatu data berupa relasi antara satu relasi dengan relasi yang lainnya. Algoritma Apriori biasa juga digunakan oleh penelitian terdahulu dalam penentuan sistem persediaan barang, dalam penentuan penjualan barang terbanyak, dalam menentukan jenis tingkat kejahatan dijalanan, prediksi penentuaan penyediaan alat-alat rumah sakit, alat-alat tempur dalam perang dan lainnya[7]-[9].

Diharapkan dengan adanya penelitian ini dapat mencapai tujuan dan informasi yang ingin diperoleh dan menjadi strategi dalam penjualan tanaman hias yang akan digunakan secara komputerisasi dan membantu mempermudah dalam pencarian informasi dari data set yang sangat banyak.

\section{METODOLOGI PENELITIAN}

Dalam penelitian ini peneliti menggunakan metode penelitian kuantatif yaitu metode yang bersifat sistematis dan matematis, dalam pengambilan data dan pengumpulan data peneliti melakukan tahapan wawancara langsung terhadap narasumber dan selanjutnya melakukan interview, tahapan selanjutnya merupakan dokumentasi terhadap lokasi penelitian pada Toko Flores Elishabet[10].

Dalam penelitian ini peneliti juga meninjau dari beberapa penelitian terdahulu sebagai bahan referensi dalam mengemukakan kebenaran dan keakuratan dari penggunaan metode apriori, diharapkan penelitian ini dapat membantu dalam strategi penjualan pada Toko Flores Elishabet. Penelitian ini bersifat replicability yaitu penelitian dapat dilakukan secara berulang bertujuan agar mendapatkan hasil yang lebih bernilai dan dapat digunakan kembali oleh penelitian selanjutnya seperti penerapan ataupun penggunaan bantuan aplikasi berupa Tanagra dalam pengujian ulang yang membuktikan kebenaran dan keakuratan terhadap hasil pengujian yang telah dilakukan peneliti terdahulunya[11].

\section{HASIL DAN PEMBAHASAN}

Pada analisa ini dilakukan analisa data penjualan yang ada pada Toko Flores Elishabet, pada data penjualan ini terdapat data yang sangat besar dan sangat banyak sehingga memerlukan waktu yang lama terhadap pemeriksaan data dari tanaman hias yang terjual dan tanaman hias yang memerlukan penyetokan yang banyak yang didapat dari data penjualan tanaman hias[12].

Tabel 1. Transaksi Tanaman Hias

\begin{tabular}{cl}
\hline No ID & \multicolumn{1}{c}{ Item Transaksi } \\
\hline 001 & Anggrek, Boroco, Bunga Matahari, Air Mancur, Kamboja Jepang \\
002 & Alamanda, Beringin, Asoka \\
003 & Air Mancur, Kamboja Jepang, Anggrek, \\
004 & Biduri, Zodia, Pisang Kipas, Palem Raja, Philodendron \\
005 & Lidah Mertua, Pohon Mangga, Palem Raja \\
006 & Airis, Lidah Mertua, Anggrek \\
007 & Lidah Mertua, Asoka, Bonsai, Anggrek, Lotus \\
008 & Mawar, Lavender, Lidah Mertua \\
009 & Pohon Mangga, Bonsai, Mawar, \\
010 & Kumis Kucing, Pinang Merah \\
011 & Bunga Terompet, Mawar, Anggrek \\
012 & Airis, Palem Raja \\
013 & Palem Raja, Teratai, Melati \\
014 & Bidara, Mawar, Pohon Mangga \\
015 & Jambu Madu, Mawar, Lavender, Lidah Mertua, Airis \\
016 & Bonsai, Airis, Lidah Mertua \\
017 & Bonsai, Biduri, Pisang Kipas \\
018 & Palem Raja, Lotus, Airis, Lidah Mertua \\
019 & Bonsai, Palem Raja \\
020 & Bonsai, Anggrek, Lotus \\
\hline
\end{tabular}


JURNAL MEDIA INFORMATIKA BUDIDARMA

Volume 4, Nomor 2, April 2020, Page 472-478

ISSN 2614-5278 (media cetak), ISSN 2548-8368 (media online)

Available Online at https://ejurnal.stmik-budidarma.ac.id/index.php/mib

DOI 10.30865/mib.v4i2.2110

\subsection{Analisa Pola Frekuensi Tinggi}

Pada tahapan ini yaitu mencari pola frekuensi tinggi dimana kombinasi item yang telah memenuhi syarat minimum dari nilai support dalam sebuah database, sebelum mencari pola frekuensi tinggi, terlebih dahulu harus diketahui jenis-jenis atau nama-nama tanaman hias yang ada dalam transaksi penjualan tanaman hias dan tentukan masingmasing support tiap-tiap item (jenis tanaman hias) dengan menggunakan rumus sebagai berikut[13]:

Tabel 2. Daftar Transaksi Tanaman Hias

\begin{tabular}{clc}
\hline No & Tanaman Hias & jumlah item \\
\hline 1 & Air Mancur & 2 \\
2 & Airis & 5 \\
3 & Alamanda & 1 \\
4 & Anggrek & 6 \\
5 & Asoka & 2 \\
6 & Beringin & 1 \\
7 & Bidara & 1 \\
8 & Biduri & 2 \\
9 & Bonsai & 6 \\
10 & Boroco & 1 \\
11 & Bunga Matahari & 1 \\
12 & Bunga Terompet & 1 \\
13 & Jambu Madu & 1 \\
14 & Kamboja Jepang & 2 \\
15 & Kumis Kucing & 1 \\
16 & Lavender & 2 \\
17 & Lidah Mertua & 7 \\
18 & Lotus & 3 \\
19 & Mawar & 5 \\
20 & Melati & 1 \\
21 & Palem Raja & 6 \\
22 & Philodendron & 1 \\
23 & Pinang Merah & 1 \\
24 & Pisang Kipas & 2 \\
25 & Pohon Mangga & 3 \\
26 & Teratai & 1 \\
27 & Zodia & 1 \\
\hline
\end{tabular}

Nilai support sebuah item diperoleh dengan rumus berikut[14]:

$$
\text { Support } A=\frac{\sum \text { JumlahTransaksi Mengandung } A}{\sum \text { Total Transaksi }}
$$

Untuk 2 item dapat diperoleh dengan rumus berikut:

$$
\text { Support }(A, B)=\frac{\begin{array}{c}
\text { Support }(\mathrm{A}, \mathrm{B})=\mathrm{P}(\mathrm{A} \cap \mathrm{B}) \\
\sum \text { Jumlah Transaksi Mengandung AdanB }
\end{array}}{\sum \text { Total Transaksi }}
$$

Berikut ini penyelesaian dalam pembentukan $\mathrm{C} 1$ atau 1 itemset

1. Air Terjun $=\frac{\sum \text { Jumlah Transaksi Mengandung Air Terjun }}{\sum \text { Total Transaksi }}=\frac{2}{20} \times 100 \%=0.1$

2. Airis $=\frac{\sum \text { Jumlah Transaksi Mengandung Airis }}{\sum \text { Total Transaksi }}=\frac{5}{20} \times 100 \%=0.25$

3. Alamanda $=\frac{\sum \text { Jumlah Transaksi Mengandung Alamanda }}{\sum \text { Total Transaksi }}=\frac{1}{20} \times 100 \%=0.05$

4. Anggrek $=\frac{\sum \text { Jumlah Transaksi Mengandung Anggrek }}{\sum \text { Total Transaksi }}=\frac{6}{20} \times 100 \%=0.3$

5. Asoka $=\frac{\sum \text { JumlahTransaksi Mengandung Asoka }}{\sum \text { Total Transaksi }}=\frac{2}{20} \times 100 \%=0.1$ dan lakukan perhitungan selanjutnya hingga tanaman hias zodia

Tabel 3. Item set dan nilai support

\begin{tabular}{cccc}
\hline No & Tanaman Hias & Jumlah item & Support \\
\hline 1 & Air Mancur & 2 & $10 \%$ \\
2 & Airis & 5 & $25 \%$ \\
\hline
\end{tabular}


JURNAL MEDIA INFORMATIKA BUDIDARMA

Volume 4, Nomor 2, April 2020, Page 472-478

ISSN 2614-5278 (media cetak), ISSN 2548-8368 (media online)

Available Online at https://ejurnal.stmik-budidarma.ac.id/index.php/mib DOI 10.30865/mib.v4i2.2110

\begin{tabular}{|c|c|c|c|}
\hline 3 & Alamanda & 1 & $5 \%$ \\
\hline 4 & Anggrek & 6 & $30 \%$ \\
\hline 5 & Asoka & 2 & $10 \%$ \\
\hline 6 & Beringin & 1 & $5 \%$ \\
\hline 7 & Bidara & 1 & $5 \%$ \\
\hline 8 & Biduri & 2 & $10 \%$ \\
\hline 9 & Bonsai & 6 & $30 \%$ \\
\hline 10 & Boroco & 1 & $5 \%$ \\
\hline 11 & Bunga Matahari & 1 & $5 \%$ \\
\hline 12 & Bunga Terompet & 1 & $5 \%$ \\
\hline 13 & Jambu Madu & 1 & $5 \%$ \\
\hline 14 & Kamboja Jepang & 2 & $10 \%$ \\
\hline 15 & Kumis Kucing & 1 & $5 \%$ \\
\hline 16 & Lavender & 2 & $10 \%$ \\
\hline 17 & Lidah Mertua & 7 & $35 \%$ \\
\hline 18 & Lotus & 3 & $15 \%$ \\
\hline 19 & Mawar & 5 & $25 \%$ \\
\hline 20 & Melati & 1 & $5 \%$ \\
\hline 21 & Palem Raja & 6 & $30 \%$ \\
\hline 22 & Philodendron & 1 & $5 \%$ \\
\hline 23 & Pinang Merah & 1 & $5 \%$ \\
\hline 24 & Pisang Kipas & 2 & $10 \%$ \\
\hline 25 & Pohon Mangga & 3 & $15 \%$ \\
\hline 26 & Teratai & 1 & $5 \%$ \\
\hline 27 & Zodia & 1 & $5 \%$ \\
\hline
\end{tabular}

Langkah selanjutnya data tanaman hias yang akan dianalisis adalah yang memiliki support minimum sebesar $15 \%$, support $100 \%$ itu sendiri merupakan persentasi dari jumlah tiap item dan berikut ini merupakan tabel dari tanaman hias atau item yang memenuhi minimum support sebagai berikut:

Tabel 4. Item set yang memenuhi minimum support

\begin{tabular}{ccc}
\hline No & $\begin{array}{c}\text { Tanaman Hias } \\
\text { (Item) }\end{array}$ & Support \\
\hline 1 & Airis & $25 \%$ \\
2 & Anggrek & $30 \%$ \\
3 & Bonsai & $30 \%$ \\
4 & Lidah Mertua & $35 \%$ \\
5 & Lotus & $15 \%$ \\
6 & Mawar & $25 \%$ \\
7 & Palem Raja & $30 \%$ \\
8 & Pohon Mangga & $15 \%$ \\
\hline
\end{tabular}

Tabel diatas nantinya akan digunakan untuk pembentukan support k-item set dan mencari nilai confidence[14].

\subsection{Pembentukan Pola Kombinasi Dua Item Set}

Pola kombinasi dua item set ini dilakukan dengan cara mengkombinasikan tiap-tiap item sebanyak dua kali kombinasi, mencari k-item selanjutnya masih menggunakan dan berpatokan pada minumum support sebagai berikut:

Lakukan seperti langkah 1 mencari nilai support yang terdapat pada k-item set 2 sebagai berikut:

Tabel 5. Kombinasi k-item set 2

\begin{tabular}{clc}
\hline No & \multicolumn{1}{c}{ Tanaman Hias (Item) } & $\begin{array}{c}\text { Jumlah } \\
\text { Item }\end{array}$ \\
\hline 1 & Airis, Anggrek & 1 \\
2 & Airis, Bonsai & 1 \\
3 & Airis, Lidah Mertua & 4 \\
4 & Airis, Lotus & 1 \\
5 & Airis, Mawar & 1 \\
6 & Airis, Palem Raja & 2 \\
7 & Airis, Pohon Mangga & 0 \\
8 & Anggrek, Bonsai & 2 \\
9 & Anggrek, Lidah Mertua & 2
\end{tabular}


JURNAL MEDIA INFORMATIKA BUDIDARMA

Volume 4, Nomor 2, April 2020, Page 472-478

ISSN 2614-5278 (media cetak), ISSN 2548-8368 (media online)

Available Online at https://ejurnal.stmik-budidarma.ac.id/index.php/mib DOI 10.30865/mib.v4i2.2110

10 Anggrek, Lotus 2

11 Anggrek, Mawar 1

12 Anggrek, Palam Raja 0

13 Anggrek, Pohon Mangga 0

14 Bonsai, Lidah Mertua 2

15 Bonsai, Lotus 2

16 Bonsai, Mawar 1

17 Bonsai, Palem Raja 1

18 Bonsai, Pohon Mangga 1

19 Lidah Mertua, Lotus 2

20 Lidah Mertua, Mawar 2

21 Lidah Mertua, Palam Raja 2

22 Lidah Mertua, Pohon Mangga 1

23 Lotus, Mawar 0

24 Lotus, Palem Raja 1

25 Lotus, Pohon Mangga 0

26 Mawar, Palem Raja 0

27 Mawar, Pohon Managga 2

28 Palem Raja, Pohon Mangga 1

1. Airis, Anggrek $=\frac{\sum \text { Jumlah Transaksi Mengandung Airis, Anggrek }}{\sum \text { Total Transaksi }}=\frac{1}{20} \times 100 \%=5 \%$

2. Airis, bonsai $=\frac{\sum \text { Jumlah Transaksi Mengandung Airis,Bonsai }}{\sum \text { Total Transaksi }}=\frac{1}{20} \times 100 \%=5 \%$

3. Airis, Lidah Mertua $=\frac{\sum \text { Jumlah Transaksi Mengandung Airis,Lidah Mertua }}{\sum \text { Total Transaksi }}=\frac{4}{20} \times 100 \%=20 \%$

4. Airis, Lotus $=\frac{\sum \text { Jumlah Transaksi Mengandung Airis,Lotus }}{\sum \text { Total Transaksi }}=\frac{1}{20} \times 100 \%=5 \%$

5. Airis, Mawar $=\frac{\sum \text { Jumlah Transaksi Mengandung Airis,Mawar }}{\sum \text { TotalTransaksi }}=\frac{1}{20} \times 100 \%=5 \%$

Tabel 6. Kombinasi k-item set 2 dan Nilai Minumum Support

\begin{tabular}{clcc}
\hline No & \multicolumn{1}{c}{ Tanaman Hias (Item) } & $\begin{array}{c}\text { Jumlah } \\
\text { Item }\end{array}$ & Support \\
\hline 1 & Airis, Anggrek & 1 & $5 \%$ \\
2 & Airis, Bonsai & 1 & $5 \%$ \\
3 & Airis, Lidah Mertua & 4 & $20 \%$ \\
4 & Airis, Lotus & 1 & $5 \%$ \\
5 & Airis, Mawar & 1 & $5 \%$ \\
6 & Airis, Palem Raja & 2 & $10 \%$ \\
7 & Airis, Pohon Mangga & 0 & 0 \\
8 & Anggrek, Bonsai & 2 & $10 \%$ \\
9 & Anggrek, Lidah Mertua & 2 & $10 \%$ \\
10 & Anggrek, Lotus & 2 & $10 \%$ \\
11 & Anggrek, Mawar & 1 & $5 \%$ \\
12 & Anggrek, Palam Raja & 0 & 0 \\
13 & Anggrek, Pohon Mangga & 0 & 0 \\
14 & Bonsai, Lidah Mertua & 2 & $10 \%$ \\
15 & Bonsai, Lotus & 2 & $10 \%$ \\
16 & Bonsai, Mawar & 1 & $5 \%$ \\
17 & Bonsai, Palem Raja & 1 & $5 \%$ \\
18 & Bonsai, Pohon Mangga & 1 & $5 \%$ \\
19 & Lidah Mertua, Lotus & 2 & $10 \%$ \\
20 & Lidah Mertua, Mawar & 2 & $10 \%$ \\
21 & Lidah Mertua, Palam Raja & 2 & $10 \%$ \\
22 & Lidah Mertua, Pohon Mangga & 1 & $5 \%$ \\
23 & Lotus, Mawar & 0 & 0 \\
24 & Lotus, Palem Raja & 1 & $5 \%$ \\
& & &
\end{tabular}


ISSN 2614-5278 (media cetak), ISSN 2548-8368 (media online)

Available Online at https://ejurnal.stmik-budidarma.ac.id/index.php/mib DOI $10.30865 /$ mib.v4i2.2110

\begin{tabular}{lllc}
25 & Lotus, Pohon Mangga & 0 & 0 \\
26 & Mawar, Palem Raja & 0 & 0 \\
27 & Mawar, Pohon Managga & 2 & $10 \%$ \\
28 & Palem Raja, Pohon Mangga & 1 & $5 \%$ \\
\hline
\end{tabular}

Berikut ini merupakan k-item set 2 yang sudah memenuhi minimum support $15 \%$ :

Tabel 7. Item set 2 yang memenuhi minimum support

\begin{tabular}{ccc}
\hline No & $\begin{array}{c}\text { Tanaman Hias } \\
(\text { Item) }\end{array}$ & Support \\
\hline 1 & Airis, Lidah Mertua & $20 \%$ \\
\hline
\end{tabular}

Pada tabel 6 menunjukan bahwasannya tidak ada lagi kombinasi yang dapat dibentuk untuk k-itemset selanjutnya, transaksi terbanyak ada pada jenis tanaman hias airis dan lidah mertua yang memenuhi pola frekuensi tinggi. paling banyak dalam transaksi yang berarti kombinasi antara dua item set tersebut adalah yang paling banyak diminati oleh konsumen dan juga diupayakan penyediaan stok tanaman airis dan lidah mertua dapat dipasok dengan baik agar tidak terjadi kekosongan barang yang paling diminati[15].

\subsection{Pola Aturan Asosiasi}

Setelah pola frekuensi tinggi ditemukan, langkah selanjutnya adalah mencari aturan asosiasi atau disebut dengan mencari nilai confidence (nilai kepastian) yang akan melihat seberapa kuatnya hubungan atara itemset dengan itemset lainnya, menetapkan nilai confidence adalah 35\% dapat dicari dengan rumus sebagai berikut:

$$
\text { Confidence }=P(A \mid B)=\frac{\sum \text { Jumlah Transaksi Mengandung AdanB }}{\sum \text { Total Transaksi Mengandung } A}
$$

Tabel 8. Menentukan Aturan Asosiasi

\begin{tabular}{|c|c|c|c|}
\hline No & Kombinasi Item set & \multicolumn{2}{|c|}{ Confidence } \\
\hline 1 & $\begin{array}{l}\text { Jika memberi tanaman hias Airis maka akan } \\
\text { membeli tanaman hias Lidah mertua }\end{array}$ & $2 / 5$ & $40 \%$ \\
\hline 2 & $\begin{array}{c}\text { Jika memberi tanaman hias Lidah mertua maka akan } \\
\text { membeli tanaman hias Airis }\end{array}$ & $2 / 7$ & $28.6 \%$ \\
\hline
\end{tabular}

Tabel 9. Hasil Aturan Asosiasi yang Terbentuk

\begin{tabular}{cccc}
\hline No & $\begin{array}{c}\text { Tanaman Hias } \\
\text { (Item) }\end{array}$ & Support & Confidence \\
\hline 1 & Airis, Lidah Mertua & $20 \%$ & $40 \%$ \\
\hline
\end{tabular}

\section{KESIMPULAN}

Dari pembahasan diatas dapat disimpulkan bahwasannya:

1. Dalam pencarian data transaksi penjualan tanaman hias didapatkan informasi dari banyaknya data jenis pembelian tanaman hias yang paling banyak diminati oleh pembeli dan disandingkan dengan jenis tanaman lainnya yang terlihat dalam pencarian data penjualan atau data transaksi tanaman hias.

2. Pembelian jenis tanaman yang sering muncul secara bersamaan dapat membantu pemilik toko tanaman hias dalam menyusun tata letak jenis tanaman hias yang paling sering dibeli bersamaan agar mempermudah pembeli melihat jenis bunga yang ingin dibeli.

3. Penerapan hasil kombinasi menggunakan Algoritma Apriori akan dapat membantu dalam mengembangkan minat dan daya Tarik pembeli tanaman hias dengan kemudahan pencarian jenis tanaman hias dan terus tersedianya stok jenis tanaman hias juga merupakan strategi dalam membantu pemasaran tanaman hias yang dianggap selalu bisa mengantisipasi kemungkinan yang akan terjadi dari informasi yang diperoleh.

\section{REFERENCES}

[1] P. de Groot, "The economics of global warming," Int. Aff., vol. 69, no. 2, pp. 371-372, 1993.

[2] Effendi Wahyono, "GO GREEN SEBAGAI SALAH SATU MODEL PENDIDIKAN KARAKTER," Model Pendidik. Karakter, 2017.

[3] Z. R. Anandhita, "ANALISIS ATAS DESAIN WEBSITE ECOMMERCE PADA ZGS GAME SHOP (Studi Kasus Pengguna Website Pada Mahasiswa Di Fakultas Ilmu Administrasi Universitas Brawijaya)," J. Adm. Bisnis, vol. 9, no. $1,2014$.

[4] D. C. Hartini, E. L. Ruskan, and A. Ibrahim, "Sistem Pendukung Keputusan Pemilihan Hotel Di Kota Palembang Dengan Metode Simple Additive Weighting (SAW)," J. Sist. Inf., vol. 5, no. 1, pp. 546-565, 2013.

[5] Y. Mahena, M. Rusli, and E. Winarso, "Prediksi Harga Emas Dunia Sebagai Pendukung Keputusan Investasi Saham 
JURNAL MEDIA INFORMATIKA BUDIDARMA

Volume 4, Nomor 2, April 2020, Page 472-478

ISSN 2614-5278 (media cetak), ISSN 2548-8368 (media online)

Available Online at https://ejurnal.stmik-budidarma.ac.id/index.php/mib

DOI 10.30865/mib.v4i2.2110

Emas Menggunakan Teknik Data Mining,” Kalbiscentia J. Sains dan Teknol., vol. 2, no. 1, pp. 36-51, 2015.

[6] J. Han, M. Kamber, and J. Pei, Data Mining Concepts and Techniques. .

[7] N. Adha, L. T. Sianturi, and E. R. Siagian, "IMPLEMENTASI DATA MINING PENJUALAN SABUN DENGAN MENGGUNAKAN METODE APRIORI ( Studi Kasus: PT. Unilever),” Maj. Ilm. INTI, vol. 12, no. 2, pp. 219-223, 2017.

[8] E. Buulolo, "Implementasi Algoritma Apriori Pada Sistem Persediaan Obat ( Studi Kasus : Apotik Rumah Sakit Estomihi Medan )," Pelita Inform. Budi Dharma, vol. 4, no. Agustus 2013, pp. 71-83, 2013.

[9] E. Buulolo, Data Mining Untuk Perguruan Tinggi, 1st ed. Yogyakarta: Deepublish, 2020.

[10] S. Effendi and Tukiran, Metode Penelitian Survei, II. Jakarta: LP3ES, 2012.

[11] D. N. Hidayat, "Dikotomi Kualitatif - Kuantitatif Dan Varian Paradigmatik Dalam Penelitian Kualitatif," Scriptura, vol. 2, no. 2, pp. 81-94, 2009.

[12] A. Nursikuwagus and T. Hartono, "Implementasi Algoritma Apriori Untuk Analisis Penjualan Dengan Berbasis Web," Simetris J. Tek. Mesin, Elektro dan Ilmu Komput., vol. 7, no. 2, p. 701, 2016.

[13] P. H. Simbolon, "Implementasi Data Mining Pada Sistem Persediaan Barang Menggunakan Algoritma Apriori ( Studi Kasus : Srikandi Cash Credit Elektronic dan Furniture ),” J. Ris. Komput., vol. 6, no. 4, pp. 401-406, 2019.

[14] B. R. B. Purba, N. A. Hasibuan, G. L. Ginting, and S. Suginam, "Implementasi Algoritma Apriori Untuk Mencari Relasi Pada Transaksi Pembelian Alat-Alat Kesehatan," JURIKOM (Jurnal Ris. Komputer), vol. 5, no. 3, pp. 269-277, 2018.

[15] D. Prasada, "KREATIF Jurnal Ilmiah Prodi Manajemen Universitas Pamulang, Volume 7, No 1 Juni 2019," Kreat. J. Ilm. Prodi Manaj. Univ. Pamulang, vol. 7, no. 1, pp. 55-65, 2019. 